\title{
ÁFRICA IMAGINÁRIA: A PRÁTICA PEDAGÓGICA NO CONTEXTO DA LEI I0.639/2003
}

\author{
Elisângela de Jesus SANTOS* \\ Sérgio Luiz de SOUZA**
}

RESUMO: O presente artigo reflete sobre o universo das expressóes culturais de grupos náo hegemônicos na contemporaneidade enquanto partes integrantes de contextos e práticas pedagógicas. Além disso, quer pensar através do Projeto Viagem pela África as artes e festividades negras enquanto expressóes fundamentais para aplicação da Lei 10.639/2003 no sistema escolar brasileiro.

PALAVRAS-CHAVE: Práticas pedagógicas. Lei 10.639/2003. Memória. Oralidades. Cultura negra. África imaginária.

\section{Introdução}

O eixo principal desta comunicaçáo considera expressôes culturais como forma de empoderamento político dos grupos que as reproduzem, bem como seus trânsitos, acesso e instrumentalização das novas mídias e tecnologias, além de suas formas de uso de políticas públicas de promoção cultural junto ao Estado brasileiro e, sobretudo no âmbito escolar, na forma da Lei 10.639/2003.

\footnotetext{
* Professora EBTT. CEFET - Centro Federal de Educação Tecnológica. Programa de PósGraduação em Relações Étnico-Raciais. Bacharelado em Línguas Estrangeiras Aplicadas às Negociaçôes Internacionais. Campus Maracaná. Rio de Janeiro - RJ - Brasil. 20271-110. lili.libelula@gmail.com.

** UNIR - Universidade Federal de Rondônia. Departamento de Ciências Sociais. Porto Velho - RO - Brasil - 76801-059 - sergiosouza@unir.br.
} 
Para pensarmos expressóes culturais em contexto étnico-racial, bem como em outros contextos, percebemos que há imensa dificuldade em definir sem correr o risco de "fixar" um conceito de cultura. Para Muniz Sodré (1988), nossa moderna noção de cultura está profundamente vinculada à constituição do Estado nacional. $\mathrm{O}$ autor considera que o termo "cultura" no pós-renascimento é retomado da noção grega de paideia, associado aos processos de educação do cidadão ajustado à polis por meio do "conjunto da poesia, artes, ciências e leis" semelhante ao que os romanos entenderiam depois por cultura animi, a formação humanista do indivíduo (SODRÉ, 1988, p. 19-20).

Como num processo de mão-dupla, as questôes culturais implicam uma dada condição social e vice-versa. A situação social dos indivíduos intervém na materialização dos processos culturais, resultando em processos de classificaçóes e representaçóes que atribuem valores hierarquizantes e desiguais às relaçôes humanas estabelecidas e vividas em sociedade.

De toda forma, para os fins que resultam este artigo, pretendemos superar tal dificuldade conforme construirmos o debate, levando em conta intercâmbios entre diversas modalidades de expressão e práticas culturais sejam populares e eruditas e os movimentos de gestão pública da cultura no âmbito da educação escolar. Em conjunto com as noçôes já constituídas há também o universo das práticas culturais percebidas no/através do contato vivo com os grupos/setores produtores de cultura.

Uma postura analítica se faz essencial para o caso brasileiro, haja vista sua condição de sociedade das mais desiguais do mundo. Desde o período colonial, houve a constituição de grupos hegemônicos que engendraram processos de desigualdade nas esferas políticas, cognitivas e socioculturais que não foram resolvidas com a constituição do Estado republicano. Esses processos de exclusão, sobretudo do ponto de vista étnico-racial, resultam na negação de nossa matriz cultural pluriétnica, constituindo dinâmicas fundadas na repressão e em tentativas de uniformização das diferenças, estabelecendo uma sociedade em que à maioria da população é negado o direito de vivenciar e exprimir referências culturais, étnicas e de memórias próprias.

Desde finais do século XIX as elites nacionais, ofuscadas ou inferiorizadas diante da imagem do que chamam de modernidade e 'pri- 
meiro mundo' construída em função da Europa, pretendem projetar o Brasil numa espécie de mão-única da história forjada na ideia de progresso. Nesta empreitada pelo "moderno", mecanismos foram criados nas esferas públicas e privadas, a exemplo das organizaçóes escolares, que muitas vezes adotam práticas que objetivam "cristalizar" a memória que reside em poucos lugares e pertence a muito poucos. É também no espaço escolar onde se forjam concepçóes de patrimônio histórico destituídos de toda historicidade, reforçando e sacralizando a história dos grupos hegemônicos como se tal história específica fosse comum a todos os grupos existentes na sociedade.

A atribuição de significados sociais que minimizam as práticas culturais de negros, indígenas e demais grupos, cujas expressôes culturais não partilham dos cânones hegemônicos, constitui um discurso social que justifica hierarquias fundadas na desigualdade de condiçôes sócio-histórico-político-cognitivo-culturais, privilegiando um determinado status étnico e de classe como supostamente refinado, padrão ou pretensamente erudito.

A observação das múltiplas dimensões que compóem a trama social, incluindo a dimensão simbólica e a superação de abordagens mecanicistas sobre os grupos estudados, pode contribuir para ampliar a percepção e enriquecer suas interpretaçóes sobre o plano social. Entendemos que a possibilidade de compreensão das lógicas específicas, presentes nos espaços de convivência onde os contingentes negro-populares estabeleceram seus territórios na sociedade brasileira, surge por meio de um olhar que considera a dinâmica própria de suas práticas culturais.

Os descendentes de africanos no Brasil, ao reconhecerem tanto os limites oficiais legais quanto os limites de um ambiente sociocultural racista, reinventam os usos e os significados dos materiais e dos espaços impostos pelas elites resistindo a partir de suas próprias concepçôes de mundo e de acordo com os seus interesses. Estes processos de reinvenção são pautados nas visóes específicas dos grupos negros e resultam numa reinterpretação de manifestaçóes culturais e formas de comunicação, possibilitando condiçôes de dialogar com os demais grupos em sociedade reelaborando os espaços de integração a fim de superar a repressão, o racismo e a exclusão social (CHAUí, 1986).

Perceber a criação das diferentes manifestaçôes políticas e socioculturais dos grupos humanos de forma ampla requer um mergulho nos 
contextos de vida onde estas manifestaçôes ocorreram, possibilitando a compreensão dos sentidos que os próprios agentes deram às suas ações em seu contexto social e histórico. Percebendo como se realiza a dinâmica entre a bagagem cultural de determinados grupos e a cultura hegemônica, podemos verificar as formas de ser, os modos de convivência, a visão de mundo e os anseios característicos dos grupos estudados. Em suma, tratamos de temas relativos à sua memória e aos processos de formaçáo da identidade-alteridade de grupos sociais específicos em um determinado momento histórico:

[...] o estudo das expressóes do universo da cultura popular, como formas de entretenimento, vida familiar e relaçôes de vizinhança podem constituir, pois, uma orientaçáo privilegiada para emendar alguns aspectos das orientaçóes políticas e dos movimentos sociais populares. A permanência de suas estruturas, a periodicidade de suas celebraçôes e o seu significado para a comunidade faz desse espaço o depositário de aspiraçôes sempre adiadas, mas continuamente renovadas no interior desses centros de reprodução do imaginário popular (MAGNANI, 1998, p. 30).

Nesta dinâmica, as populaçóes negras criaram espaços que tanto marcaram profundamente a formação social brasileira, como se tornaram suportes materiais fundamentais para a organização dos grupos e dos lastros comunitários que constituíram a substância social dos lugares das memórias dos descendentes de africanos deste país (SOUZA, 2007). Entendemos aqui a memória enquanto um conjunto de signos e símbolos compartilhados pelos grupos sociais, referências criadas ao longo do tempo e estabelecidas em determinados espaços, sendo estes últimos concebidos tanto em suas dimensôes físicas quanto simbólicas uma vez que:

É sobre o espaço, sobre o nosso espaço aquele que ocupamos, por onde sempre passamos, ao qual sempre temos acesso, e que em todo caso, nossa imaginação ou nosso pensamento é a cada momento capaz de reconstruir que devemos voltar nossa atenção; é sobre ele que nosso pensamento deve se fixar, para que reapareça esta ou aquela categoria de lembranças (HALBWACHS, 1990, p.143).

Faz-se necessário reconhecer o caráter subversivo das memórias subterrâneas, as quais, de maneira quase imperceptível, no silêncio, 
resistem ao excesso de discursos e à doutrinação ideológica da memória oficial. Além do trabalho realizado acerca dos relatos orais da população negra em diferentes contextos, dialogamos com os propósitos de aplicação da lei 10.639/2003, constituindo práticas pedagógicas que valorizem as manifestaçóes culturais do universo afro-brasileiro e africano no contexto educacional brasileiro.

\section{Viagem imaginária pela África como prática pedagógica}

Como possibilidades efetivas de construção de discursos e de memória social que contribuam para formas de re-conhecimento das representaçóes negras em nossa sociedade, descreveremos breve relato de atividade desenvolvida como contação de histórias, pesquisa histórica, oficinas de artes plásticas e elaboração de textos pautada por uma viagem imaginária ao continente africano. A atividade foi realizada na rede escolar do município de Araraquara, Estado de São Paulo, Brasil. É importante ressaltar que o trabalho que relatamos foi desenvolvido pela professora de Artes, Ana Lúcia da Silva, a quem dedicamos a publicação deste artigo. A professora Ana faleceu em 2011 e teve a vida toda dedicada à Educação, particularmente ao Ensino de Artes. A ela pertencem todos os créditos deste trabalho.

Egito, Costa do Marfim, Moçambique, Angola foram países africanos visitados pela imaginação de crianças da rede pública de ensino fundamental conduzidos pelo trabalho da professora Ana. Assim, o ambiente de estudo, a sala de aula, adquiriu nova significação. A ludicidade, própria do universo infantil, aliada à figura de Nelson Zulu, boneco negro e de pano, criado pela docente responsável pelo projeto, contribuíram para materializar a representação do negro e de seu universo rico em referências culturais, aguçando a curiosidade e interesse das crianças e propiciando conhecimentos sobre o continente africano, estimulando a pesquisa por meio de revistas, imagens e outras publicações impressas e virtuais.

No que tange aos conteúdos de História, Geografia e Ciências, as crianças puderam conhecer e se expressar acerca dos seguintes temas: localização espacial dos países estudados (países, principais cidades, capitais); atividades econômicas e de lazer (parques, feiras, safáris); paisagens naturais (praias, fauna, regiôes); construçóes arquitetônicas de diferentes naturezas (museus, centros comerciais); produção cultu- 
ral, industrial e artística (costumes, crenças, música, dança, artesanato, produtos); meios de transporte para acesso ao Continente Africano (aéreo ou marítimo).

Quanto aos conteúdos de Língua Portuguesa, foram utilizados como suporte de texto: a revista turística criada pelos alunos e alunas; abordagem de gêneros textuais informativos e persuasivos, ricos em formas escritas, recursos gráficos, diagramação, imagens e slogans característicos da propaganda. A revista caracterizava-se por textos curtos e simples atendendo à linguagem coloquial, sonoridade, atendimento à razão e à emoção, organização e relação das palavras e imagens nos espaços da página, com frases de impacto. Também se pode despertar do desejo e do interesse por viagens a outros países além da constituição de um vocabulário específico e criar recursos estilísticos.

A junção professora-conteúdo-aluno é fundamental em projetos como este, cujo resultado da avaliação não se limita ao desempenho dos alunos, mas envolve também o desempenho de professores e professoras. Toda prática de construção de memória de um grupo social é intrínseca à esfera do conhecimento que se tem e se constrói sobre ele e por ele (MARTÍN-BARBERO, 2009). Muito embora a cultura do país tenha incorporado várias das referências culturais negras para formar a pluralidade cultural que a caracteriza, essas referências muitas vezes são "esquecidas" e desassociadas de suas matrizes negras.

Considerando a importância da produção artística como expressão dos grupos humanos em sociedade, os conhecimentos sobre a arte quando difundidos na sala de aula podem ser um poderoso instrumento de luta para a dissolução das representaçóes estereotipadas das quais estamos tratando. $\mathrm{O}$ estímulo à arte muito contribui para a formação de agentes criativos e críticos, sensíveis ao mundo que rodeia alunos, curiosos por conhecer e apreciar a diversidade cultural característica de seu país, compreendendo e valorizando suas especificidades e procurando superar preconceitos, manifestaçóes de intolerância e discriminação presentes nas relações entre as pessoas.

O projeto Viagem pela África foi uma iniciativa de sucesso neste sentido. A proposta tem o intuito de recriar e valorizar a história e os modos de ser e de viver dos povos negros de origem africana, negligenciados ao longo da história do povo brasileiro e em decorrência 
do privilégio de valores pautados pela cultura europeia pretensamente hegemônica.

No âmbito das políticas públicas brasileiras, o ano de 2003 marca a alteração da Lei n. 9.394 de 1996 pela Lei 10.639, que estabelece a obrigatoriedade da temática "História e Cultura Afro-Brasileira" no currículo oficial da Rede de Ensino. A partir da nova lei, os conteúdos referentes à História e à Cultura Afro-Brasileira passam a ser ministrados em todo o currículo escolar, em especial nas áreas de Educação Artística, de Literatura e História Brasileiras (BRASIL, 2003).

Uma das experiências interessantes e constitutivas do projeto em questão foi o esforço de colocar em prática conhecimentos e procedimentos adquiridos por meio de cursos de formação docente. Disso resultou a elaboração e execução de projetos sobre os grupos étnicos, constituintes da formação do povo brasileiro, promovendo discussóes com os alunos e alunas sobre os temas que constituem sua memória, abordando suas origens familiares para acionar os conhecimentos que tinham sobre seus antepassados, além de propor o exercício de refletir acerca dos lugares de onde vieram e os grupos étnicos aos quais pertenciam.

A partir desta primeira abordagem, tratando da questão da memória dos alunos e alunas, alguns dos posicionamentos e concepçóes que as crianças expressavam sobre a temática eram muito significativos: muitos alunos negros não se reconheciam como afro-descendentes já que a identidade de africanos e seus descendentes estavam associadas exclusivamente à história da escravização. Como resultado do desconhecimento que os alunos tinham de sua própria história, diversidade cultural, atividades econômicas e produçôes artísticas, havia muito preconceito em relação a alguns elementos da cultura africana, sobretudo os relacionados à religiosidade: os orixás e os termos/palavras de origem/matriz africana.

A palavra macumba pode ser lida como o exemplo clássico, largamente entendida com sentidos pejorativos. A noção de que os africanos constituíam um único povo também era um equívoco largamente difundido, tornando invisíveis as particularidades relativas às origens territorial e cultural de cada povo do continente. Entre outros equívocos, havia a crença recorrente de que a África era um lugar atrasado e selvagem. As crianças não imaginavam, por exemplo, que o Egito está situado no continente africano e negligencia- 
vam a existência de grandes centros comerciais, hotéis e parques como equipamentos passíveis de existência nas cidades mais populosas e urbanizadas da África.

\section{Observaçóes sobre as possibilidades ou acerca de resultados}

A sociedade brasileira reproduz, na linguagem e na prática cotidiana, repertórios cognitivos repletos de significados estereotipados sobre grupos negros no Brasil, e ainda em relação ao continente africano e suas populações (SANTOS, 2013). Situações como estas reforçam a importância da experiência da viagem imaginária realizada por professores e por crianças no contexto escolar, à África.

Os resultados da atividade proposta denotam ainda que, por terem estudado o continente negro, os alunos puderam alcançar primeiro, no plano do imaginário e depois, no plano social, representaçóes mais próximas da realidade do negro brasileiro e africano - e de suas próprias realidades, para o caso dos alunos afrodescendentes - o que, em consequência, os aproximam do continente africano e dos povos negros - para não dizer de si mesmos.

Deve-se acrescentar a estes resultados, o incremento das potencialidades de entendimento e de re-conhecimento dos alunos e alunas, dos significados das expressóes e práticas artísticas e sócio-histórico-culturais dos grupos negros estudados. $\mathrm{Na}$ companhia de Nelson Zulu, a sala de aula e universo do/sobre o negro foram re-significados.

$\mathrm{O}$ objetivo de inserir no universo infantil ou infanto-juvenil questóes tão complexas contempla inicialmente, propostas de sensibilização tais como a viagem imaginária pelo continente africano. Práticas pedagógicas como essas visam estabelecer proximidade e interação com os colegas de sala, desenvolvem a expressão artística dos alunos e exercitam a experiência coletiva do lúdico, fortalecendo também as relaçóes entre professor-aluno no contexto escolar (BARBOSA, 1991).

Este movimento deve ser realizado no sentido de provocar curiosidades, comunicação, emoçóes, busca de informaçôes, questionamentos, criação, descobertas, valores e desenvolvimento das habilidades de expressão dos sujeitos envolvidos. O projeto objetivou tratar da história, da cultura, da economia, da geografia e da arte dos povos africanos, destacando suas diferentes identidades, linguagens artísticas, 
paisagens naturais e urbanas, meios de desenvolvimento econômico, organização social, entre outros aspectos.

O projeto Viagem pela África foi organizado em oito oficinas que estimulavam a percepção e a imaginação criadora das crianças contribuindo para ampliar seus universos socioculturais por meio da difusão das tradiçôes, músicas, danças, rituais, jogos, narrativas míticas e históricas, organização política, social e econômica, valores estéticos do povo africano e dos afro-brasileiros. Realizado durante o primeiro semestre de 2008, o projeto focalizava as formas de pensar e viver destes povos e culminou na elaboração de uma revista de propaganda turística sobre vários países que compóem o continente africano.

Figuras 1 e 2: Atividades: criação de páginas da revista. Moçambique/Capa/safári/índice

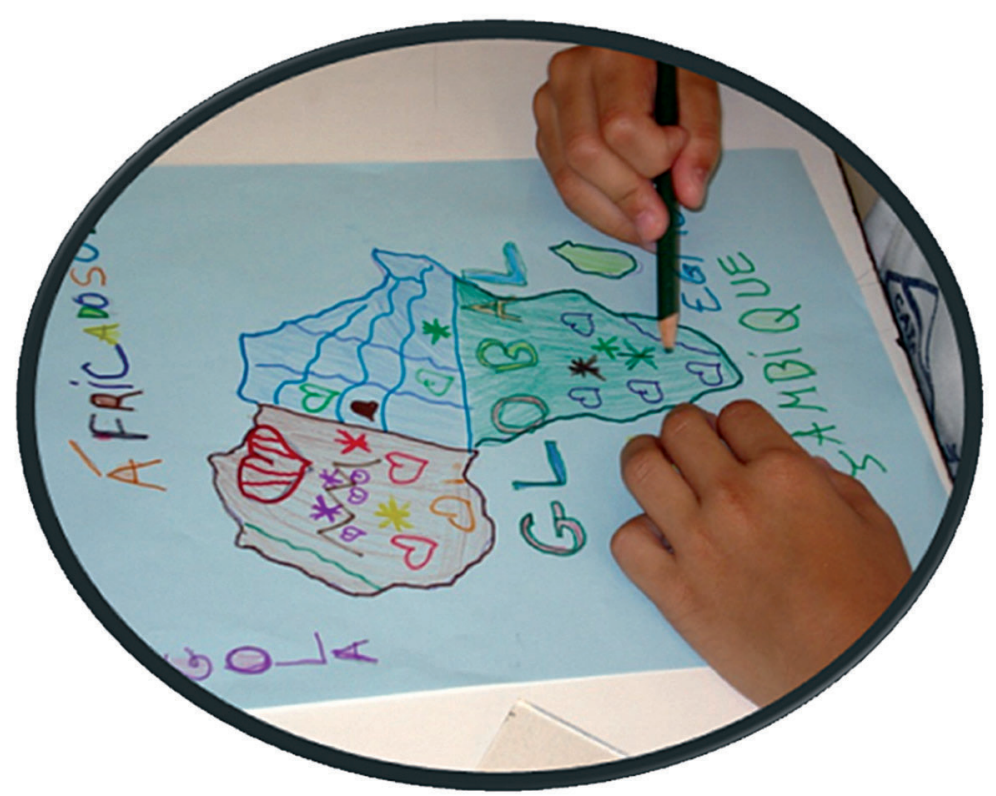




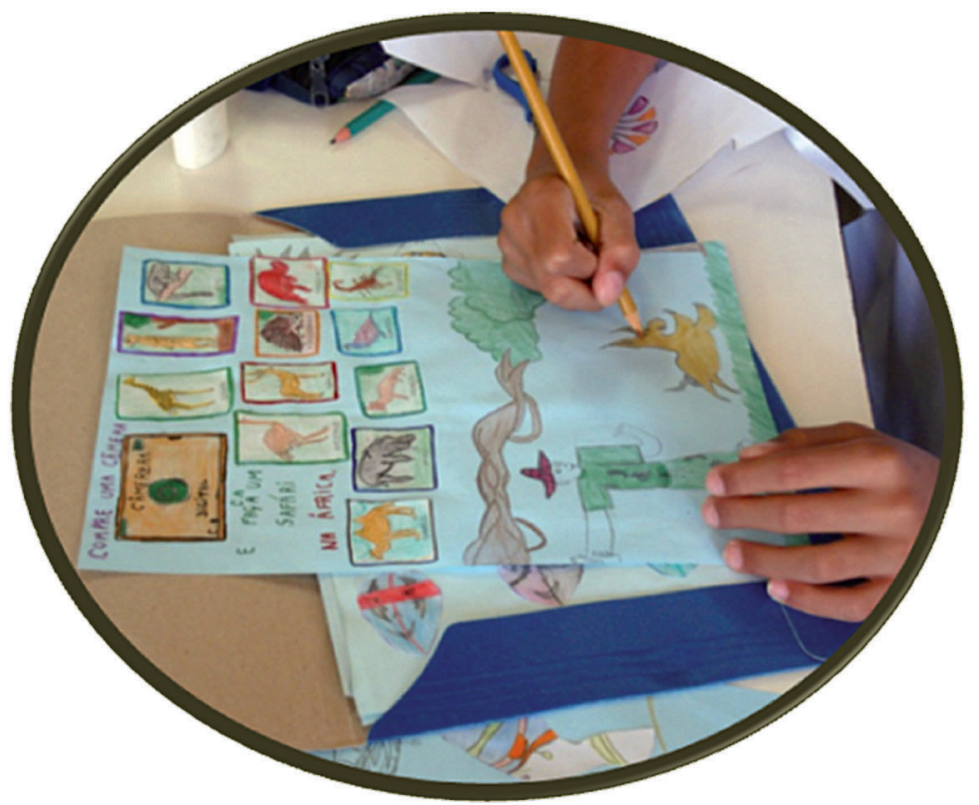

Fonte: Fotos dos autores.

Isto não significou, na experiência do trabalho docente, reduzir a aula com a linguagem dramática, limitando-a aos momentos alegres, divertidos e prazerosos - o riso é uma das manifestaçôes de conhecimento e de expressão mais importantes da vida humana, muito embora seja constantemente reprimido na sala de aula. $\mathrm{O}$ ato de rir pôde proporcionar às crianças a compreensão dos conteúdos de Arte relacionada ao desenvolvimento cognitivo, social, afetivo, perceptivo, bem como à capacidade de criar e observar criticamente o mundo em que se vive. Este riso criativo resultou diversos momentos de discussão e reflexão com as crianças. $\mathrm{O}$ desenvolvimento do projeto contemplou questóes relativas às desigualdades sociais e o preconceito relacionado à vida dos africanos e seus descendentes em nosso país. 
A preocupação que situava o trabalho esteve voltada para o desenvolvimento de uma visão cultural, social e estética desprovida de estereótipos sobre os povos africanos, focando a ampliação de conhecimentos sobre o assunto e a análise crítica de imagens, sentimentos, atitudes, comportamentos e valores que assimilamos durante o processo de socialização e de aprendizagem escolar. Enquanto educadores, continuamos a reproduzir e a transmitir, sem questionamentos, representaçóes equivocadas e racistas sobre os grupos negros e os diferentes povos no Brasil e do mundo. O projeto Viagem pela África visa realizar movimentos de superação destes processos, contribuindo também para a superação do racismo no contexto escolar.

Perspectivas e experiências que vão além das aparências e das representaçôes sociais impostas, por grupos hegemônicos, aos negros e negras ou qualquer outro grupo não hegemônico em nossa sociedade e que percebam ambivalências na existência dos sujeitos e diferentes sentidos nas diversas trocas culturais, serão capazes de captar as singularidades e infinitas possibilidades das manifestações artísticas e culturais plurais. É este olhar que procuramos aguçar em nossos estudos e é este o sentido deste trabalho.

\section{Agradecimentos e dedicatória}

Este texto é dedicado à memória de Ana Lúcia da Silva (19662011) que teve toda uma vida dedicada ao ofício e missão do professorado no Ensino de Artes/Educação Artística em escolas públicas do município de Araraquara/SP e região. Ana que foi quem criou e realizou o Projeto "Viagem à África" e foi quem produziu todas as informaçōes relativas ao texto e fotos que fomentaram esse artigo. É a ela a quem agradecemos por nos dar a honra de organizar as informaçóes para "fazer ventar" os frutos de seu trabalho, pois os dados do projeto aqui reunidos foram entregues por ela ao Catavento Grupo de Estudos e Pesquisas, grupo associado ao CLADIN/LEAD/ NUPE da Faculdade de Ciências e Letras da UNESP de Araraquara, do qual Ana fez parte. É com o sentimento de que de muitas outras sementes possam brotar deste trabalho, comprometido com as questôes étnico-raciais e efetiva aplicação da Lei 10.639/2003 em todas as esferas de ensino do país, que também dedicamos este texto à filha de Ana, Júlia. 


\section{IMAGINARY AFRICA: THE PRACTICE TEACHING IN THE CONTEXT OF LAW IO.639 / 2003}

ABSTRACT: This article reflects on the universe of cultural expressions of non-hegemonic groups in contemporary society as an integral part of contexts and pedagogical practices. Also, we want to think through the Africa Travel Design arts and black festivities as fundamental expressions to the application of Law 10.639 / 2003 in the Brazilian school system.

KEYWORDS: Pedagogical practices. Law 10.639 / 2003. Memory. Orality. Black culture. Imaginary Africa.

\section{REFERÊNCIAS}

BARBOSA, A. M. A Imagem no Ensino da Arte: anos oitenta e novos tempos. São Paulo: Iochpe: Perspectiva, 1991.

BRASIL. Lei 10.639, de 9 de janeiro de 2003. Altera a Lei no 9.394, de 20 de dezembro de 1996, que estabelece as diretrizes e bases da educação nacional, para incluir no currículo oficial da Rede de Ensino a obrigatoriedade da temática "História e Cultura Afro-Brasileira", e dá outras providências. Diário Oficial da União, Brasília, DF, 2003. Disponível em: <http://www.planalto.gov.br/ccivil_03/Leis/2003/ L10.639.htm>. Acesso em: 3 dez. 2015.

CHAUÍ, M. Conformismo e Resistência. São Paulo: Brasiliense, 1986.

HALBWACHS, M. A Memória Coletiva. São Paulo: Vertice, 1990.

MARTÍN-BARBERO, J. Dos meios às mediaçóes: comunicação, cultura e hegemonia. Rio de Janeiro: UFRJ, 2009.

MAGNANI, J. G. C. Festa no Pedaço: cultura popular e lazer na cidade. São Paulo: Ed. da Unesp: Hucitec, 1998.

SANTOS, E. de J. Entre Improvisos e Desafios: do cururu como cosmovisão de grupos caipiras no Médio Tietê, SP. 300f. 2013. Tese 
(Doutorado em Ciências Sociais) - Programa de Pós-Graduação em Ciências Sociais, Universidade Estadual Paulista, Araraquara, jul. 2013.

SOUZA, S. L. ( $\mathbf{R e})$ vivências negras: entre batuques, bailados e devoçôes: práticas culturais e territórios negros no interior paulista (1910-1950). Ribeirão Preto: Edição do autor, 2007. 230 p.

SODRÉ, M. A Verdade Seduzida: por um conceito de cultura no Brasil. São Paulo: Francisco Alves, 1988. 
